\title{
EVALUATING REFINERY SUPPLY CHAIN POLICIES AND INVESTMENT DECISIONS THROUGH SIMULATION-OPTIMIZATION
}

\author{
Lee Ying Koo \\ Yuhong Chen \\ Department of Chemical and \\ Biomolecular Engineering \\ National University of Singapore \\ 4 Engineering Drive 4 \\ Singapore 117576, SINGAPORE
}

\author{
Arief Adhitya \\ Process Science and Modeling \\ Institute of Chemical and Engineering \\ Sciences \\ 1 Pesek Road, Jurong Island \\ Singapore 627833, SINGAPORE
}

\author{
Rajagopalan Srinivasan \\ Iftekhar A. Karimi \\ Department of Chemical and \\ Biomolecular Engineering \\ National University of Singapore \\ 4 Engineering Drive 4 \\ Singapore 117576, SINGAPORE
}

\begin{abstract}
The dynamic, non-linear, and complex nature of a supply chain with numerous interactions among its entities are best evaluated using simulation models. The optimization of such system is not amenable to mathematical programming approaches. The simulation-optimization method seems to be the most promising. In this paper, we look at a refinery supply chain simulation and attempt to optimize the refinery operating policies and capacity investments by employing a genetic algorithm. The refinery supply chain is complex with multiple, distributed, and disparate entities which operate their functions based on certain policies. Policy and investment decisions have significant impact on the refinery bottom line. To optimize them, we develop a simple simulation-optimization framework by combining the refinery supply chain simulator called Integrated Refinery In Silico (IRIS) and genetic algorithm. Results indicate that the proposed framework works well for optimization of supply chain policy and investment decisions.
\end{abstract}

\section{INTRODUCTION}

Today's organizations face cut-throat competition and operate in uncertain market situations. Complex supplier relationships and unreliable sources of material supply on one side, and ever-increasing customer expectations on the other side, greatly pile the pressure on supply chains to operate most efficiently for maximum profitability. Supply chains are becoming more complex as companies focus on their core competencies and outsource other activities. This results in an increased number of players in a supply chain and a complex maze of feedback loops. Unpredictable dynamics, information delay, disparate entities with varying goals, disruptions, and tightened regulations further add to the complexities. Accordingly, supply chain problems continue to attract much attention.
This paper specifically deals with the petroleum refinery supply chains. Refining is a complex process which transforms crude oil into valuable products such as gasoline, heating oil, jet fuel, lubricants and intermediates for further processing to produce plastics, paints, fertilizers, detergents, etc. The industry is highly capital-intensive, and mostly high-volume and low-margin. The refinery supply chains have distinctive features which differentiate them from other industries and require special attention, as discussed in the next paragraph.

Crude oil is produced in both ground fields and offshore platforms, and is transported mostly via large ships called Very Large Crude Carriers (VLCCs) to various refineries located around the world. Transportation times are relatively long; it takes 4-6 weeks for a VLCC carrying crude oil from the Middle East to reach refineries in Asia. Furthermore, the price of crude oil is very volatile even on a daily basis. Similarly, product demands and prices are highly fluctuating. Numerous products and their variants can be produced from a crude by suitably altering the complex manufacturing process consisting of highly interconnected system of reactors, separators, and blenders. The yields of the different products from different crudes are different and so are the operating costs. Other key features of the refinery supply chain are huge inventories, need for safety-first, sensitivity to socio-political uncertainties, environmental regulations, and extensive trading. All of these pose challenges in logistics planning, production planning, scheduling, and other supply chain management (SCM) efforts unique to the refinery industry.

Operating in the kind of environment discussed above, the refinery adopts certain policies in performing its supply chain functions such as crude procurement, storage, production, and product delivery. These policies directly affect the refinery's performance and have a significant impact on its long-term profitability. Classical optimization techniques based on mathematical programming generally 
work well for small-scale, short-term supply chain problems, about 2-4 weeks in size. However, they have not been successful in dealing with stochastic, large-scale, long-term, integrated, dynamic problems such as evaluating supply chain policies and investment decisions, which have long-term impact (months to years). At present, simulation remains the predominant methodology for dealing with such problems. To exploit the advantages of optimization while managing the complexities at the same time, the current trend is towards synergistic union of simulation and optimization ( $\mathrm{Fu} \mathrm{2001),} \mathrm{which} \mathrm{is} \mathrm{adopted} \mathrm{in} \mathrm{this} \mathrm{paper.} \mathrm{In}$ this work, we use a dynamic refinery supply chain simulator, called Integrated Refinery In Silico (IRIS), developed by Pitty et al. (2005), to evaluate the effect of supply chain policies and investment decisions on the supply chain. Optimization is performed using genetic algorithm.

The main objective of this paper is to affirm that optimal supply chain policy and investment decisions can be identified using the simulation-optimization framework to assist in identifying the optimal decisions. The remainder of the paper is organized as follows. Section 2 states the problem description and Section 3 presents a brief literature review of related works. Section 4 describes the proposed simulation-optimization method. Case study results will be discussed in Section 5. Finally, Section 6 discusses the conclusion and future work.

\section{PROBLEM DESCRIPTION}

Figure 1 shows the entities involved in a typical refinery supply chain and their interactions (Pitty et al. 2005). External entities include suppliers, $3^{\text {rd }}$ party logistics providers (3PLs), shippers, jetty, and customers. Internal entities are the refinery functional departments: procurement, operations, sales, storage, and logistics. IRIS models all these entities and simulates the activities in the supply chain starting from demand forecasting, crude procurement, logistics arrangement, crude delivery, crude storage, operations planning and scheduling, crude processing, product storage, to product delivery. The solid arcs in Figure 1 represent material flows. Crude oil flows from suppliers to shipper, jetty, crude tanks, and finally to processing units. After processing, products flow from blend tanks to product tanks, shipper, and finally to customers. The dotted arcs represent information flows between the various entities.

The various departments perform their functions according to certain supply chain policies. In this paper, we are concerned with the crude procurement policy of the procurement department, the crude storage policy of the storage department, and the production policy of the operations department. The crude procurement policy determines how the refinery selects crude to purchase and estimates how much to buy, which supplier to buy from, and when the crude should be delivered to the refinery. The crude storage policy specifies which tank the crude should be stored in and when to unload the crude. The production policy decides how much crude to process and which production mode to run. These policies are dependent on certain parameters. In this work we seek to optimize them. These parameters are summarized in Table 1 and explained in the next paragraph.

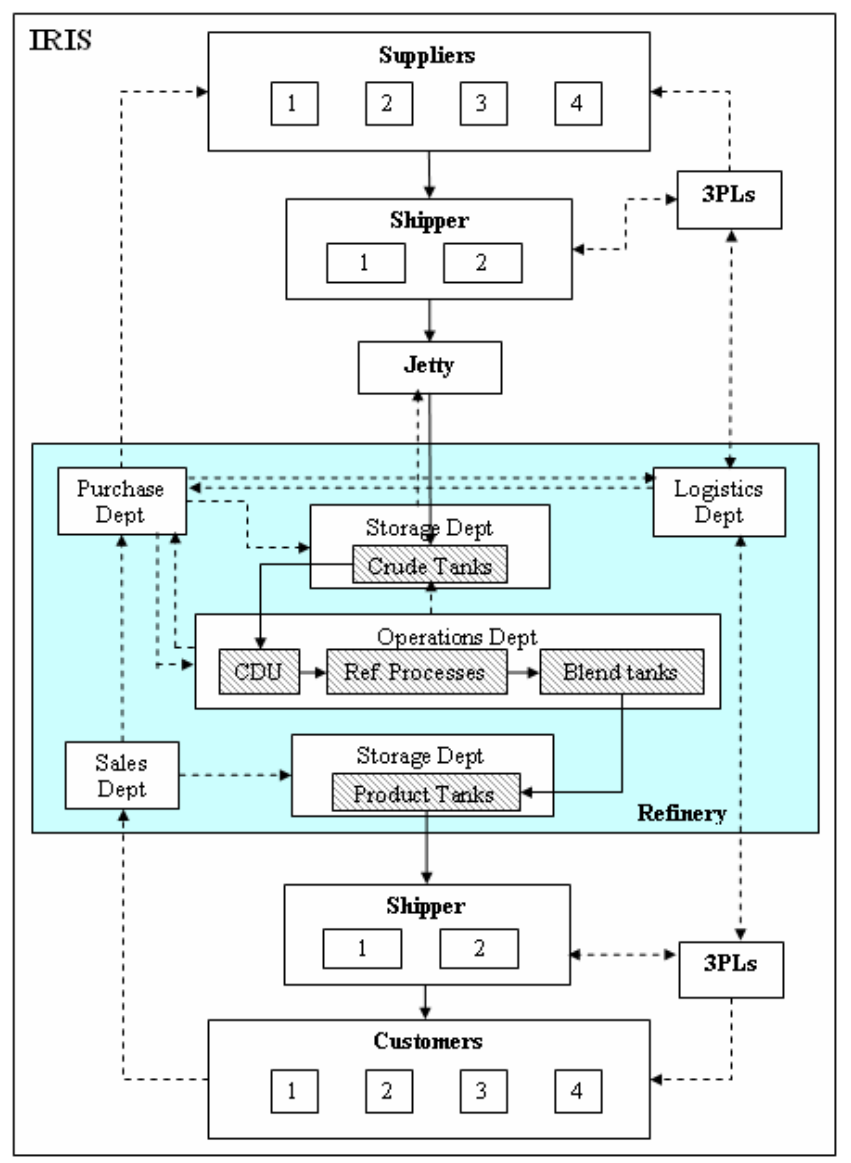

Figure 1: Typical Refinery Supply Chain

Table 1: Parameters to be Optimized

\begin{tabular}{|l|l|l|}
\hline \multicolumn{1}{|c|}{ Department } & \multicolumn{1}{|c|}{ Policy } & \multicolumn{1}{c|}{ Parameters } \\
\hline Procurement & $\begin{array}{l}\text { Crude } \\
\text { procure- } \\
\text { ment }\end{array}$ & $\begin{array}{l}\text { Planning horizon; } \\
\text { Procurement cycle time }\end{array}$ \\
\hline Storage & $\begin{array}{l}\text { Crude } \\
\text { storage }\end{array}$ & Crude tank capacity \\
\hline Operations & $\begin{array}{l}\text { Produc- } \\
\text { tion }\end{array}$ & $\begin{array}{l}\text { Production cycle time; } \\
\text { CDU throughput limit }\end{array}$ \\
\hline
\end{tabular}

Parameters related to the crude procurement policy are planning horizon and procurement cycle time. Planning horizon is the time span for which procurement is planned in advance. Procurement cycle time is the frequency at which procurement is made and products are shipped. Parameters related to the crude storage policy are the crude tank capacities, which can be increased by investing a certain 
capital cost. Parameters related to the production policy are production cycle time and CDU throughput limit debottlenecking. Production cycle time is the frequency at which the throughput and the production mode can be changed, as a refinery generally operates in "time blocks", during which the crude slate feeding the crude distillation unit (CDU) remains the same. In this work, we assume that the refinery can increase its maximum throughput limit by investing a certain capital cost for debottlenecking.

There are tradeoffs involved in each of these parameters. Long planning horizon means less accurate demand forecasts as it is more difficult to predict further into the future, but it allows more time for managing disruptions such as ship delay, for example by emergency procurement. Long procurement cycle time implies more crude is purchased in each cycle and higher crude storage capacity is needed, but it allows more time to meet demands as product shipments are less often. Long production cycle time means less flexibility but higher cost savings due to less changeover cost. The opportunity for increased production, which comes from having additional crude tank capacity and higher CDU maximum throughput limit, involves capital costs.

The problem is then to find the optimal values for these parameters to maximize profit to the refinery. Profit is calculated as product revenue less sum of crude purchase cost, crude inventory cost, product inventory cost, operating cost, changeover cost, penalty for unfulfilled demand, capital cost, and demurrage cost. We group the parameters into two problems: policy decisions (procurement cycle time, planning horizon, and production cycle time) and investment decisions (crude tank capacity and CDU throughput limit debottlenecking).

\section{LITERATURE REVIEW}

Most works in the literature on refinery optimization deal with sub-sections of the refinery such as crude oil scheduling, production planning, gasoline blending, crude selection, etc. The majority are based on mathematical programming. Neiro and Pinto (2004) and Reddy et al. (2004) give a comprehensive review of works related to optimization in the refinery supply chain.

Interestingly, similar trend is observed for refinery supply chain simulation. Most works on refinery supply chain simulation reported in the literature address only a part of the supply chain, such as crude transportation logistics using discrete event simulation and optimal control (Cheng and Duran, 2004), simulation-based short-term scheduling of crude oil from port to refinery tanks and distillation unit (Chryssolouris et al., 2005), agent-based crude procurement (Julka et al., 2002).

Outside the refinery context, Banks et al. (2002) survey many SCM simulation studies at IBM and Virtual Logistics and discuss issues related to strategic and opera- tional SCM, distributed SCM simulation, and commercial packages for SCM simulation. Kleijnen (2005) distinguish four types of simulation - spreadsheet simulation, system dynamics, discrete-event dynamic simulation, and business games) - and provide a literature review of the application of each type in SCM.

Jung et al. (2004) propose a simulation-based optimization computational framework for determining safety stock levels for planning and scheduling applications. They combine deterministic planning and scheduling models for optimization and a discrete-event simulation model. Their work is focused only on planning and scheduling.

Recently, Pitty et al. (2005) developed IRIS, an integrated model of all the entities in the refinery supply chain, so as to enable integrated and coordinated decision making. Rather than focusing on a single sub-section, they attempt to model the overall refinery supply chain. Hence, IRIS enables holistic evaluation of policies, disruption management, and supply chain analysis. Exploiting these capabilities of IRIS, we couple IRIS with genetic algorithm (GA) for our optimization purpose.

\section{PROPOSED SIMULATION-OPTIMIZATION METHOD}

Figure 2 illustrates the proposed simulation-optimization method. The user gives input such as economics data, capacity limits, demand data, yields, initial inventory, supplier data, pumping rate, etc., as simulation parameters in IRIS. The parameters to be optimized form the chromosome (or string) in GA. To evaluate the fitness of a chromosome, a simulation run in IRIS based on those parameters is executed. After the simulation is completed, IRIS evaluates the objective value, in this case profit, and returns it to GA. The profit is used by GA as the fitness value for ranking the chromosomes. The GA procedure used in this work is illustrated in Figure 3.

As seen in Figure 3, a new generation is produced via crossover and mutation operations. Crossover is conducted by randomly selecting two parent strings from the population and performing crossover functions on them. Three types of crossover are used: arithmetic, heuristic and simple. Arithmetic crossover takes two parents and performs an interpolation along the line formed by the two parents. Heuristic crossover performs an extrapolation along the line formed by the two parents outward in the direction of the better parent. Simple crossover chooses a random crossing site along the parent length and performs a crossover. The number of times crossover is performed in each population is defined by the user through the crossover rate parameters. 


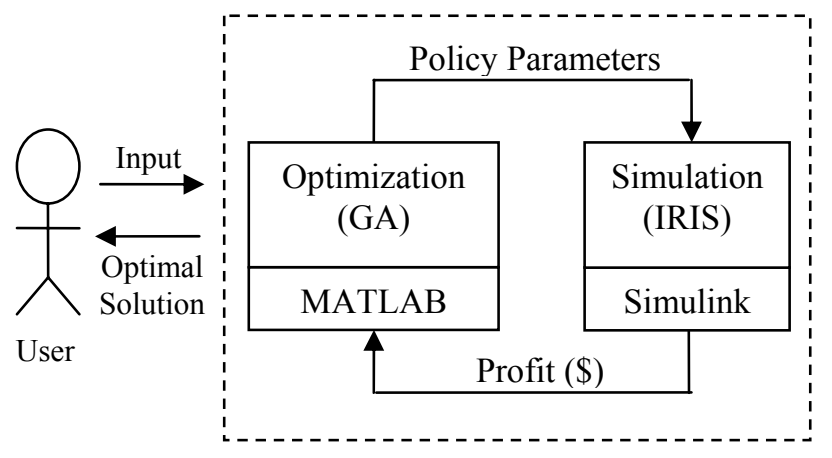

Figure 2: Proposed Simulation-Optimization Method

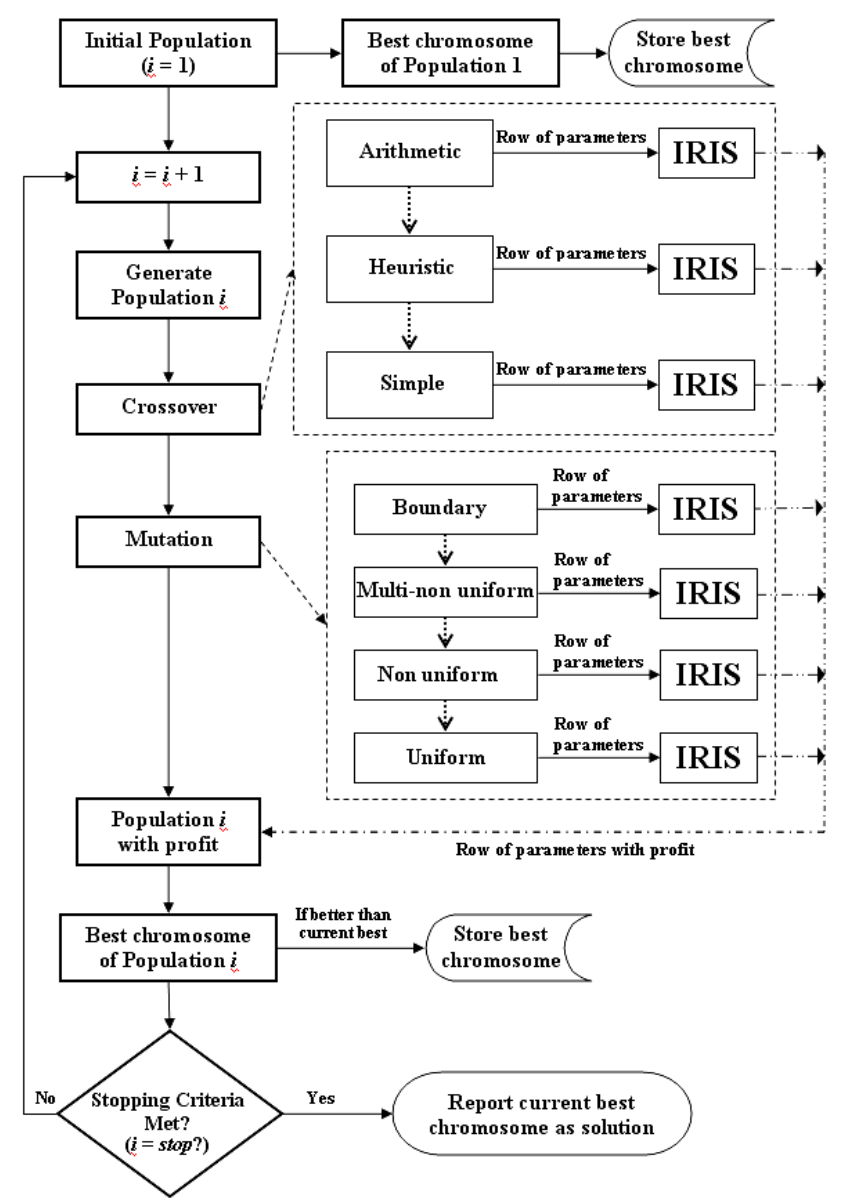

Figure 3: Genetic Algorithm Procedure

Mutation is conducted by randomly selecting one parent string from the population and performing mutation function on it. Four types of mutations are used: boundary, multi-non-uniform, non-uniform and uniform. Boundary mutation takes one of the parameters of the parent and changes it randomly either to its upper or lower bound. Multi-non-uniform mutation changes all, while nonuniform mutation changes one, of the parameters of the parent based on a non-uniform probability distribution. This Gaussian distribution starts wide, and narrows to a point distribution as the generations progress. Uniform mutation changes one of the parameters of the parent based on a uniform probability distribution. The number of times mutation is performed in each population is defined by the user through the mutation rate parameters.

Each string is sent to IRIS for simulation and the resulting profit is sent back to GA. The best string from each generation is saved into the store matrix if it is better than the current best in the store matrix. GA will terminate after a user-defined number of generations has been reached and the best string in the store matrix will be reported.

\section{CASE STUDY}

The data for the refinery supply chain case study is shown in Table 2. As the base case, we assume that the refinery currently operates with planning horizon $=40$ days, procurement cycle time $=7$ days, and production cycle time $=$ 7 days. We have used the simulation-optimization strategy to solve two different problems: (1) policy decisions and (2) investment decisions. The range of the parameters used in GA are listed in Table 3.

Table 2: Data for the Case Study

\begin{tabular}{|c|c|}
\hline Parameter & Value \\
\hline Jetty pumping rate (kbbl/hr) & 75 \\
\hline $\begin{array}{l}\text { VLCC allowable wait time be- } \\
\text { fore demurrage (days) }\end{array}$ & 1 \\
\hline Number of crudes & 5 \\
\hline Initial crude inventory & 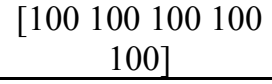 \\
\hline $\begin{array}{l}\text { Max. crude storage capacity } \\
\text { limit (kbbl) }\end{array}$ & $\begin{array}{l}{\left[\begin{array}{llll}1250 & 1250 & 1250 \\
1250 & 1250\end{array}\right]}\end{array}$ \\
\hline Max. throughput (kbbl/day) & 250 \\
\hline Min. throughput (kbbl/day) & 100 \\
\hline Number of products & 4 \\
\hline Initial product inventory & {$\left[\begin{array}{lllll}200 & 200 & 200 & 200\end{array}\right]$} \\
\hline Product price $(\$ / \mathrm{kbbl})$ & {$\left[\begin{array}{lllll}79 & 76 & 68 & 47\end{array}\right]$} \\
\hline Crude price $(\$ / \mathrm{kbbl})$ & {$\left[\begin{array}{llllll}5 & 56 & 53 & 50 & 52\end{array}\right]$} \\
\hline Demurrage charge (\$/day) & 50000 \\
\hline Operating cost $(\$ / \mathrm{kbbl})$ & 2 \\
\hline Crude inventory cost $(\$ / \mathrm{kbbl})$ & 0.05 \\
\hline Product inventory cost $(\$ / \mathrm{kbbl})$ & 0.05 \\
\hline Product deficit penalty $(\$ / \mathrm{kbbl})$ & $\left.\begin{array}{lllll}5 & 5 & 5 & 5\end{array}\right]$ \\
\hline Changeover cost (\$/event) & 100 \\
\hline
\end{tabular}

In Problem 1, crude prices, CDU yields, product prices and demands are kept consistent across different simulation runs for fair comparison. In Problem 2, they are stochastic and five simulation runs are performed for each string to get the average profit. Problem 2 is relatively small because the search space (extra crude capacity and extra throughput capacity) is discrete. However, stochasticity leads to increased complexity in the search process. The 
GA parameters used in the two problems are listed in Table 4. The results from the two problems are summarized in Table 5. The simulation horizon used in all cases is 120 days.

Table 3: Range of the Parameters Used in GA

\begin{tabular}{|l|c|}
\hline \multicolumn{1}{|c|}{ Parameter } & Range \\
\hline Planning horizon (days) & $20-50$ \\
\hline Procurement cycle time (days) & $3-15$ \\
\hline Production cycle time (days) & $3-15$ \\
\hline Possible extra crude storage ca- & $0-\$ 0$ \\
pacity (kbbl) and the correspond- & $250-\$ 500,000$ \\
ing capital cost & $500-\$ 600,000$ \\
& $750-\$ 700,000$ \\
& $1000-\$ 800,000$ \\
& $1250-\$ 900,000$ \\
\hline Possible extra throughput capacity & $0-\$ 0$ \\
from debottlenecking (kbbl/day) & $25-\$ 100,000$ \\
and the corresponding capital cost & $50-\$ 110,000$ \\
& $75-\$ 120,000$ \\
& $100-\$ 130,000$ \\
& $125-\$ 140,000$ \\
\hline
\end{tabular}

Problem 1: After optimizing the policy parameters, the profit of the refinery increases tremendously to $\$ 149.2 \mathrm{M}$ from the base case of $\$ 42.8 \mathrm{M}$. This is most significantly due to the increase in product sales. The shorter planning horizon leads to more accurate demand forecasts, which is evident from the observation that despite buying 50\% more crude than the base case (see crude cost), the average crude inventory is only slightly higher. This implies that more crude is consumed for production, as can be seen from the higher average throughput and higher operating cost. The shorter production cycle time of four days also contributes to the higher throughput, as it allows the refinery to quickly switch to high-demand products. The efficient use of crude also means storage is always available whenever crude ships arrive, resulting in zero demurrage cost. All these factors contribute to the significantly higher overall profit.

Problem 2: The optimal investment decisions identified are to add an extra crude storage capacity of $750 \mathrm{kbbl}$ and debottlenecking to have an extra $25 \mathrm{kbbl} /$ day of throughput capacity. Despite using the same policy parameters as the base case, the refinery is able to make a significantly higher profit of $\$ 73.4 \mathrm{M}$ thanks to the additional throughput capacity, which can be seen from the higher product revenue and average throughput than the base case. The higher crude storage capacity also contributes a cost saving in demurrage cost. These improvements are significant benefits for an investment of $\$ 0.8 \mathrm{M}$ in capital cost.

\section{CONCLUSIONS}

In this globalized era, supply chains operate in a challenging environment characterized by increased competition, where supply chain policy and investment decisions have significant impact on profitability. However, the complexity of refinery supply chains pose a great challenge for optimization through mathematical programming approaches.

In this paper, we developed a simulation-optimizationbased approach to support supply chain policy and investment decisions. Optimization is performed by a genetic algorithm linked to a dynamic refinery supply chain simulator. The policy decisions considered are lengths of the planning horizon, the procurement cycle time, and the production cycle time. The investment decisions considered are crude tank capacity and debottlenecking for increased throughput. Case study results show the capability of the proposed method.

\subsection{Current Work}

The simulation-optimization method requires a significantly large computation time if run on a single processor. The computation time for one simulation run in IRIS is about 45-60 seconds. For a population of 60 strings and a GA run of 30 generations, the computation time is approximately $60 \times 30 \times 45 \mathrm{~s}=81,000 \mathrm{~s} \approx 1$ day. To reduce the computation time, we are currently developing a parallel computing framework for the simulation-optimization method. In this framework, one master processor execute the GA and multiple slave processors carry out IRIS simulation in parallel. Whenever the master generates a new string from crossover or mutation, it will send the new string to a slave, which will then run IRIS based on that string. Instead of waiting for the slave to return the profit of this string, the master continues to generate another new string and sends it to another slave. After all the slaves have returned the strings and their profits to the master, the master re-assembles the population and proceeds to the next generation.

With 30 parallel slaves, the computation time required for the same 60-string population and 30 generations considered above is approximately $(60 / 30) \times 30 \times 45 \mathrm{~s}=2,700 \mathrm{~s}$ $\approx 1$ hour, which is a $95 \%$ reduction from the previous requirement of 1 day!

The improved computational speed from parallelizing the algorithm will enable statistical studies incorporating stochastic variables for more realistic analysis. Optimization of other supply chain policies will be explored. 
Koo, Chen, Adhitya, Srinivasan, and Karimi

Table 4: GA Parameters of Problems 1 and 2

\begin{tabular}{|l|c|c|}
\hline \multicolumn{1}{|c|}{ Metric } & \multicolumn{1}{|c|}{$\begin{array}{c}\text { Problem 1 } \\
\text { (Policy) }\end{array}$} & \multicolumn{1}{|c|}{$\begin{array}{c}\text { Problem 2 } \\
\text { (Investment) }\end{array}$} \\
\hline $\begin{array}{l}\text { Parameters } \\
\text { to be optimized }\end{array}$ & $\begin{array}{l}\text { 1) Planning horizon } \\
\text { 2) Production cycle } \\
\text { time }\end{array}$ & $\begin{array}{c}\text { 1) Extra crude stor- } \\
\text { age capacity limit } \\
\text { 3) Procurement cy- } \\
\text { cle time } \\
\text { limit }\end{array}$ \\
\hline Population size & 60 & 15 \\
\hline Number of generations & 20 & 20 \\
\hline Stochastic across runs? & No & Yes \\
\hline Runs per chromosome & 1 & 5 \\
\hline Number of crossover operations per generation (Crossover rate) \\
\hline Arithmetic & 2 & 1 \\
\hline Heuristic & 2 & 1 \\
\hline Simple & 2 & 1 \\
\hline Number of mutation operations per generation (Mutation rate) \\
\hline Boundary & 4 & 1 \\
\hline Multi-non-uniform & 6 & 1 \\
\hline Non-uniform & 4 & 1 \\
\hline Uniform & 4 & \multicolumn{2}{|c|}{} \\
\hline
\end{tabular}

Table 5: Base Case and Optimal Results of Problems 1 and 2

\begin{tabular}{|l|c|c|c|}
\hline \multicolumn{1}{|c|}{ Metric } & Base Case & $\begin{array}{c}\text { Problem 1 } \\
\text { (Policy) }\end{array}$ & $\begin{array}{c}\text { Problem 2 } \\
\text { (Investment) }\end{array}$ \\
\hline Parameters & & & Base \\
\hline Planning horizon (days) & 40 & 33 & Base \\
\hline Production CT (days) & 7 & 4 & 750 \\
\hline Procurement CT (days) & 7 & 5 & 25 \\
\hline $\begin{array}{l}\text { Extra crude storage capacity } \\
\text { kbbl) }\end{array}$ & 0 & Base & \\
\hline Extra throughput (kbbl/day) & 0 & Base & 1936.8 \\
\hline Performance Indicators & & & 1260.4 \\
\hline Average crude inv. $(\mathrm{kbbl})$ & 1454.0 & 1611.7 & 104.1 \\
\hline Average product inv. $(\mathrm{kbbl)}$ & 887.8 & 1150.1 & 765.8 \\
\hline Average throughput $(\mathrm{kbbd})$ & 92.7 & 162.1 & 11.7 \\
\hline Product revenue $(\$ \mathrm{M})$ & 700.0 & 1215.0 & 7.6 \\
\hline Crude cost $(\$ \mathrm{M})$ & 612.4 & 997.0 & 25.0 \\
\hline Crude inv. cost $(\$ \mathrm{M})$ & 8.7 & 9.7 & 0.8 \\
\hline Product inv. cost $(\$ \mathrm{M})$ & 5.3 & 6.9 & 1.8 \\
\hline Operating cost $(\$ \mathrm{M})$ & 22.2 & 38.9 & 3.9 \\
\hline Capital cost $(\$ \mathrm{M})$ & 0 & 0 & 0 \\
\hline Deficit penalty $(\$ \mathrm{M})$ & 4.0 & 7.6 & $\mathbf{7 3 . 4}$ \\
\hline Changeover cost $(\$ \mathrm{M})$ & 4.2 & 5.7 & \\
\hline Demurrage cost $(\$ \mathrm{M})$ & 0.4 & 0 & $\mathbf{1 4 9 . 2}$ \\
\hline Profit $(\$ \mathbf{M})$ & $\mathbf{4 2 . 8}$ & & \\
\hline
\end{tabular}




\section{ACKNOWLEDGMENTS}

The authors thank Mr. Suresh Sivanandam Pitty of Singapore Petroleum (SPC) for IRIS, the brainchild of his work and Dr. Li Wenkai of The Logistics Institute - Asia Pacific (TLIAP) for providing technical support on IRIS.

We gratefully acknowledge Dr. Jeffrey A. Joines of North Carolina State University for providing the Matlab ${ }^{\circledR}$ codes for genetic algorithm on the following website:

$<$ http://www.ie.ncsu.edu/mirage/GAToolBox/gaot/gaotind ex.html $>$.

\section{REFERENCES}

Banks, J., S. Buckley, S. Jain, and P. Lendermann 2002. Panel session: opportunities for simulation in supply chain management. In Proceedings of the 2002 Winter Simulation Conference, eds. E. Yücesan, C. H. Chen, J. L. Snowdon, and J. M. Charnes, 1652-1658. Piscataway, New Jersey: Institute of Electrical and Electronics Engineers.

Cheng, L. and M. A. Duran 2004. Logistics for world-wide crude oil transportation using discrete event simulation and optimal control. Computers and Chemical Engineering 28: 897-911.

Chryssolouris, G., N. Papakostas, and D. Mourtzis 2005. Refinery short-term scheduling with tank farm, inventory and distillation management: An integrated simulation-based approach. European Journal of Operational Research 166: 812-827.

Fu, M. C. 2001. Simulation optimization. In Proceedings of the 2001 Winter Simulation Conference, eds. B. A. Peters, J. S. Smith, D. J. Medeiros, and M. W. Rohrer, 53-61. Piscataway, New Jersey: Institute of Electrical and Electronics Engineers.

Julka, N., I. Karimi, and R. Srinivasan 2002. Agent-based supply chain management -2 : a refinery application. Computers and Chemical Engineering 26: 1771-1781.

Jung, J. Y., G. Blau, J. F. Pekny, G. V. Reklaitis, and D. Eversdyk 2004. A simulation based optimization approach to supply chain management under demand uncertainty. Computers and Chemical Engineering 28: 2087-2106.

Kleijnen, J. P. C. 2005. Supply chain simulation tools and techniques: a survey. International Journal of Simulation \& Process Modelling 1: 82-89.

Neiro, S. M. S. and J. M. Pinto 2004. A general modeling framework for the operational planning of petroleum supply chains. Computers and Chemical Engineering 28: 871-896.

Pitty, S. S., R. Srinivasan and I. A. Karimi 2005. A Novel Framework and Tool for Dynamic Simulation of Supply Chains. Presented at AIChE Annual Meeting, 30 October - 4 November, Cincinnati, USA, \#104d.
Reddy, P. C. P., I. A. Karimi, and R. Srinivasan, 2004. A novel solution approach for optimizing crude oil operations. AIChE Journal 50(6): 1177-1197.

\section{AUTHOR BIOGRAPHIES}

LEE YING KOO is an undergraduate student in the Department of Chemical and Biomolecular Engineering at the National University of Singapore. She was involved in this project while she was on industrial attachment at the Institute of Chemical and Engineering Sciences in Singapore. Her research interest is optimization and supply chains. Her e-mail address is <leeying@nus.edu.sg>.

YUHONG CHEN is a final year Chemical Engineering undergraduate student at the National University of Singapore. He became involved in this project during his final year research course. His research interest is supply chain modeling and optimization. He can be contacted at <u0204171@nus.edu.sg>.

ARIEF ADHITYA is a Research Engineer at the Institute of Chemical and Engineering Sciences in Singapore. He received the B.Eng in 2003 and M.Eng in 2005, both in Chemical Engineering and from the National University of Singapore. His current research interest is supply chain risk and disruption management. His e-mail address is <arief_adhitya@ices.a-star.edu.sg>.

RAJAGOPALAN SRINIVASAN is an Associate Professor in the Department of Chemical and Biomolecular Engineering at the National University of Singapore. He is concurrently a Senior Scientist at the Institute of Chemical and Engineering Sciences, where he leads the Process Systems and Control team. His research is targeted towards developing systems engineering approaches for benign process design, agile process control and supply chain optimization. He received his B.Tech from IIT Madras in 1993 and his PhD from Purdue University in 1998, both in Chemical Engineering. He worked as a research associate in Honeywell Technology Center, before joining NUS. His e-mail address is <rajsrinivasan@nus.edu.sg>.

I. A. KARIMI is a Professor in the Department of Chemical and Biomolecular Engineering at the National University of Singapore. He received his $\mathrm{PhD}$ from Purdue University in chemical engineering. He has worked in both academia and industry for several years. His current research interests are in the areas of process optimization, supply chain management, chemical logistics, planning and scheduling, mathematical modeling, and nonlinear dynamics. His e-mail address is <cheiak@nus.edu.sg> . 